Interactive comment on "Chlorine partitioning near the polar vortex boundary observed with ground-based FTIR and satellites at Syowa Station, Antarctica in 2007 and 2011" by Hideaki Nakajima et al.

Anonymous Referee \#3

Received and published: 24 July 2019

Review of "Chlorine partitioning near the polar vortex ..."

BY NAKAJIMA ET AL.

General

It is now more than three decades ago that the Antarctic ozone hole was discovered (WMO, 2019); by now the processes involved in its formation are thought to be under- 
stood in some detail. Current state-of-the-art models reproduce the observed springtime ozone loss in the polar stratosphere with good accuracy (e.g., Khosrawi et al., 2009; Chipperfield et al., 2017; WMO, 2019; Froidevaux et al., 2019). Nonetheless, there are open questions in Antarctic chlorine and ozone chemistry. Such questions can be addressed when new observations, such as those reported in the manuscript, become available. Insofar, this manuscript is an important contribution to ACP.

Interactive

comment

I suggest an extension of the discussion in the manuscript regarding several issues (see in particular detailed comments below). Briefly, the Cly correlation needs to be adjusted to 2007 and 2011 (or the adjustment made should be described, see below) and the model behaviour reported by Grooß et al. (2018) that I think is also found here (namely that the models show $\mathrm{HCl}$ remaining in the core of the vortex) should be discussed in terms of MIROC3.2.

Further, the manuscript could make a better contribution to addressing the issue of a "race" between chlorine activation and deactivation (Solomon et al., 2015; Müller et al., 2018; Zafar et al., 2018) and the question of which $\mathrm{HCl}$ formation processes are responsible for the observed $\mathrm{HCl}$ increase at the end of the ozone hole period.

Overall, the FTIR measurements presented here are certainly of great scientific interest and the measurements are combined in a meaningful way with satellite information. Moreover, a model simulation is included that helps the interpretation of the measurements. Notwithstanding these points, I suggest a substantial extension of the discussions on Antarctic chlorine chemistry in the paper. Provided the (in my view) necessary extensions are done, I would expect that this paper would make a great contribution to ACP. 


\section{Comments in Detail}

Year-to-year variability of Cly

The main driver for antarctic ozone loss is the available Cly but there is a substantial year-to-year variability in this quantity; this issue is discussed by Strahan et al. (2014). How are the years discussed here $(2007,2011)$ ranked in the observed variability of Cly (Strahan et al., 2014)? Further, the applicability of the employed empirical relation for Cly to the years discussed here $(2007,2011)$ needs to be addressed in the paper.

$\mathrm{HCl}$ remains in the core of the polar vortex in austral winter

The authors find here for the MIROC3.2 CCM that some $\mathrm{HCl}$ remains in winter in the core of the polar vortex in darkness. Such a model behaviour is expected as there is not enough $\mathrm{CIONO} 2$ and no light in the core of the vortex. This model behaviour was reported by Grooß et al. (2018) for three models. Further they showed that this model feature is not found in observations of $\mathrm{HCl}$. I suggest stating that the MIROC3.2 CCM shows the same issue - provided that the authors agree. If they do not agree, there should be a discussion of the issue in the paper.

Overestimated transport across the vortex edge in models

The paper states that transport across the vortex edge might be overestimated in models. I think here is the potential for the paper to make an important contribution. The issue that models might overestimate mixing into the vortex edge has been discussed (e.g.) by Hoppe et al. (2014); indeed for the same Eulerian transport scheme as employed in MIROC3.2. Observations of $\mathrm{N} 2 \mathrm{O}$ (and the $\mathrm{N} 2 \mathrm{O}$ gradient might help to eludicate the model issue. In any case a bit more discussion on this point is warranted 
The authors state the following conclusion in the paper: "Continuous loss of $\mathrm{HCl}$ was seen at $87.9^{\circ} \mathrm{S}$ between days 160 and 200 even after the disappearance of the counterpart of heterogeneous reaction (R1) (Figure 15(e)). The cause of this continuous loss was unknown until recently, where a hypothesis was proposed that includes the effect of decomposition of particulate $\mathrm{HNO} 3$ by some process like ionisation caused by galactic cosmic rays during the winter polar vortex (Grooß et al., 2018). Solomon et al. (2015) proposed a new mechanism on this issue: Continuous transport of CIONO2 from the subpolar regions near $55-65^{\circ} \mathrm{S}$ to higher latitudes near $65-75^{\circ} \mathrm{S}$ provides a flux of NOx from more sunlit latitudes into the polar vortex. Our result is consistent with the mechanism indicated by some sporadic increase in CIONO2 at around days 158, 179 , and 189 at $76.7^{\circ} \mathrm{S}$ as shown in Figure 15(f)".

First, the processes described by Grooß et al. (2018) and Solomon et al. (2015) are very different: Grooß et al. (2018) describe a polar night process, whereas Solomon et al. (2015) describe a dynamical process (acting later in the course of the existence of the polar vortex), which needs light nonetheless as formation of CIONO2 is involved.

Further note that Grooß et al. (2018) discussed the transport mechanism and concluded that it cannot explain the so-called 'HCl-discrepancy'. Of course the present manuscript might come to a different conclusion but I think a more extensive evaluation of the arguments put forward by Grooß et al. (2018) is necessary here. In this context, Fig. 15 of the manuscript could be important; could it be that the 'discrepancy' reported by Grooß et al. (2018) is also noticeable in panel (e) of Fig. 15?

Second, an alternative explanation for the continuing decline of $\mathrm{HCl}$ could be the formation of $\mathrm{HOCl}$ under sunlit conditions which would allow $\mathrm{HCl}$ to decline to zero values (Grooß et al., 2011; Müller et al., 2018). If the authors cannot develop a preference for one of these mechanisms based on their data/observations, I suggest to state both alternatives in the discussion in the paper.

Printer-friendly version

Discussion paper
Interactive

comment 
This issue reflects the importance of the reaction $\mathrm{HCl}+\mathrm{HOCl}->\mathrm{Cl} 2+\mathrm{H} 2 \mathrm{O}(\mathrm{R} 4)$; early papers (Prather, 1992; Crutzen et al., 1992) have pointed to the importance of this reaction for bringing down the $\mathrm{HCl}$ concentrations in the polar vortex in Antarctica.

Finally, the transport of $\mathrm{ClONO} 2$ from the vortex edge to the vortex core does not occur in isolation; inspection of Fig. 15 would suggest to me that mixing from the vortex edge would transport an amount of $x$ ppb of ClONO2 but at the same time an amount of $x$ $\mathrm{ppb} \mathrm{HCl}$ as well. Thus there is no net removal of $\mathrm{HCl}$ by "mixing". As stated above the easiest solution would be to discuss both alternative explanations. Further, these alternative are not necessarily contradictory; both mechanisms could contribute partly to the observed $\mathrm{HCl}$ decline.

\section{"Race" between chlorine activation and deactivation}

An aspect of polar ozone and chlorine chemistry, where different concepts are discussed in the literature is the maintenance of enhanced levels of active chlorine during the time period (September and early October) when rapid ozone loss occurs. One concept is the one of a "race" between chlorine activation and deactivation, i.e., a competition of the heterogeneous reactions $\mathrm{R} 1, \mathrm{R} 2$, and $\mathrm{R} 4$ and gas-phase reformation of $\mathrm{HCl}$ and ClONO2 (R12, R13) (Solomon et al., 2015). The other concept is the one of so-called "HCl null-cycles", where the formation of $\mathrm{HCl}(\mathrm{R} 13)$ is followed by immediate reactivation of $\mathrm{HCl}$ (Müller et al., 2018; Zafar et al., 2018). (See also the discussion in WMO, 2019). The measurements presented in this manuscript might help to shed some light on these issues - this could be a contribution of this paper. Alternatively, if the measurements presented here cannot contribute to discriminating between the two discussed processes, this could also be a result of the paper (which should be mentioned). 
The presented observations demonstrate that the deactivation in the Antarctic is through formation of $\mathrm{HCl}$ and that the deactivation is rapid. This is good and important. However, it is also stated that the formation of $\mathrm{HCl}$ is via the reaction $\mathrm{CH} 4+\mathrm{Cl}$ $->\mathrm{HCl}+\mathrm{CH} 3(\mathrm{R} 13)$. I agree that this $\mathrm{HCl}$ formation is "common wisdom" (e.g. Crutzen et al., 1992; Douglass et al., 1995). However the authors have also mentioned the reaction $\mathrm{CH} 2 \mathrm{O}+\mathrm{Cl}->\mathrm{HCl}+\mathrm{CHO}(\mathrm{R} 14)$. What is the evidence that the observed formation of $\mathrm{HCl}$ is indeed via $\mathrm{R} 13$ ? Further, it should be taken into account that there is also reactivation of chlorine even if reactions $\mathrm{R} 14$ and $\mathrm{R} 13$ occur at a considerable rate (Müller et al., 2018; Zafar et al., 2018). Again, the paper could make a contribution here, but at least there should be more discussion of all the processes playing a role here.

Negative correlation between $\mathrm{CIO}$ and $\mathrm{CIONO} 2$

The cause of the negative correlation between $\mathrm{ClO}$ and CIONO2 (e.g. Fig. 10) is discussed as being caused by the distance of Syowa station relative to the vortex. I do not think that this is entirely correct. The main reason for the negative correlation is that $\mathrm{ClO}$ is converted into $\mathrm{ClONO} 2$ and vice versa. (However the rather large scatter in Fig. 10 should also be acknowledged.) Given this fact, the higher values of CIONO2 seem to preferentially occur closer to the vortex edge (so that the location of Syowa indeed is relevant).

\section{Near zero values of ozone}

The observations of ozone reported here (ozone sonde measurements show very low values in October. Such near zero values of ozone have been reported before 
(Solomon et al., 2005); are the ozone values reported here compatible with the reported low ozone values? Perhaps the ozone values could be replotted on a log-scale as is the earlier publication (Solomon et al., 2005) - perhaps it is too much to show such plots in the paper, but an electronic supplement might be an alternative.

The FTIR measurements are a major contribution of this paper. This is why I suggest to make the data available for other researchers as well. Further Toon and Farmer (1989) have reported measurements of the $\mathrm{HOCl}$ integrated vertical column abundance, which was inferred from high resolution infrared solar spectra measured by the JPL MkIV interferometer from the NASA DC-8 aircraft during flights over Antarctica in September 1987. Would the current set-up also allow measurements of $\mathrm{HOCl}$ ? Even quantifying an upper limit might be helpful. Other species of potential interest would be methanol or formaldehyde.

\section{Model description}

The results of the MIROC3.2 model make an important contribution to the study. However, the model documentation is not sufficient. There is a short paragraph (on p. 15) and the reference to Akiyoshi et al. (2016). But even after consulting these pieces of information, many aspects of the model remain unclear. Which photolysis scheme is used for the calculations presented here; is the scheme using spherical geometry? I think a reference to the employed scheme would be appropriate. Which solver is employed for solving the set of differential equations that result from the considered chemical scheme? How exactly (which surfaces?) is heterogeneous chemistry (including particle formation) treated in the model?

Further, it is not clear which reactions (and which species) have been considered in 
the presented model calculations. But this aspect could be important. I think it would be very helpful (and very easy) to add the information in question (e.g. add a list of reactions as an electronic appendix) to the paper.

\section{Data Availability}

Interactive

comment

There is no data availability statement in this paper. According to the rules of ACP such a statement should be added to the final version of the paper. This point would both regard all observations (including FTIR, ozone sondes and the satellite information shown in the plots of the paper) and the model results. It is up to ACP, but I believe that making the data (in particularly the unique FTIR data) available would enhance the impact of this paper.

\section{Details}

- p. 2, I. 10: "and the observed"

- p. 2, I. 11: add a citation for the observed ozone hole magnitude

- p. 3, I. 5: citations for these reactions? In particularly, R14 is often mentioned regarding chlorine deactivation.

- $\mathrm{p}$ 3, I 8: $\mathrm{R} 14$ is not often mentioned as a $\mathrm{HCl}$ forming reaction; suggest adding a reference. Perhaps also for $\mathrm{R} 12$ and $\mathrm{R} 13$.

- p. 3, |21: in all years?

Printer-friendly version

- p. 3, I. 28: "sometimes" is not right, is it? It happens in the Arctic always if chlorine activation occurs, l'd argue. Probably the first observations of this phenomenon were reported by von Clarmann et al. (1993); Oelhaf et al. (1994). 
- p 4, I. 5: citation for the FTIR measurement? How much can we learn about the vertical resolution from Fig. 1?

- p 4, I. 22: Farman et al. (1985) did not show ozone sonde measurements. By the way, another ozone sonde measurement was conducted in 1985 by Gernandt (1987).

- p. 4, I 1: I think a further advantage is also the location inside and outside of the vortex core and the inner vortex transport barrier.

- p. 7, I. 19: 4.5 ppm is not the best value if dehydration occurs.

- p. 7, I. 30: have these ozone sondes been compared in sonde comparison studies?

- p. 8, I. 4: Such an empirical relation is not valid for arbitrary years: it should be explained how the adjustment to the conditions of 2007 and 2001 has been done (it is necessary to both correct $\mathrm{N} 2 \mathrm{O}$ and Cly).

- p 8., I. 14: the issue of a transport barrier within the Antarctic polar vortex was also discussed by Lee et al. (2001). The transport barrier within the Antarctic polar vortex in the early vortex can also be seen in ILAS measurements (Tilmes et al., 2006).

- $\mathrm{p}$ 8., I. 28: Within the vortex (but at the boundary) much lower $\mathrm{HCl}$ would be expected than outside of the vortex. Is this not seen by the FTIR measurements?

- p. 9, I. 3: what is the uncertainty range of the FTIR measurements? (report a \pm here).

- p. 9, I. 21: inside, but in the core or at the edge?

- p. 9., I. 26: "partitioning" is not really clear; I believe you mean $\mathrm{HCl} / \mathrm{Cly}$. 
- p. 9, I. 33: probably not via $\mathrm{R} 13$, see above.

- p. 11, I. 17: "systematically smaller": could you quantify this statement?

- p. 11, I. 19: faster mixing in the model than in the real world might indeed be an issue (see above).

- p. 11, I. 21: for which year is the correlation - the correlation need to be adjusted to the years in question here (2007 and 2011).

- p. 11., I. 32: Note that the onset of heterogeneous chemistry occurs very likely before PSCs for and that PSCs do not form at NAT equilibrium. You could formulate: temperatures low enough for the onset of heterogeneous chemistry.

- p. 11., I. 32: NO2 does not condense (it needs to be chemically converted first).

- $\mathrm{p} \mathrm{12,} \mathrm{I.} \mathrm{2:} \mathrm{"Some} \mathrm{HCl}$ remains" this is expected in the model as there is not enough $\mathrm{ClONO} 2$ (as stated here) and no light in the core of the vortex. This model behaviour was also shown by Grooß et al. (2018) and I suggest stating that the MIROC3.2 CCM shows the same issue (see also above).

- p. 12, I. 16: Note that $\mathrm{HCl}$ remains low even under these conditions, when a relatively fast rate of reaction $\mathrm{R} 13$ should occur in the stratosphere. $\mathrm{HCl}$-null cycles (Müller et al., 2018) could be an explanation.

- $p 12$, I. 21: How sure can we be that the recovery is via R13??

- p. 13., I. 10: compare Grooß et al. (2018)

- p 13, I. 22: Again, how sure can we be that the recovery is via R13?? What about $\mathrm{R} 14$ ? What about other possible $\mathrm{HCl}$ forming reactions? 
- p 13, I. 25 and below: The processes described by Grooß et al. (2018) and Solomon et al. (2015) should be distinguished: Grooß et al. (2018) describe a polar night process, whereas Solomon et al. (2015) describe a dynamical process which needs light nonetheless as formation of $\mathrm{CIONO} 2$ is involved.

- p. 14, I. 9: could you quantify "well below"

- p. 14., I. 13: the reason for the negative correlation is the conversion of $\mathrm{ClO}$ to CIONO2 (see above).

- p. 14, I. 21: As discussed above, it is not sure that the transport of CIONO2 is the only possible explanation for the behaviour of $\mathrm{HCl}$.

- p. 14., I. 23: NOx rich would also mean rich in $\mathrm{HCl}$-correct?

- p 15., I. 14: Sander et al 2010 or 2011 ? (see reference list).

- p. 16., I. 20: Stimpfle

- p. 17 , I. 29: 1977 ?

- p. 20, I. 10: Karin Labitzke

- p 22, I. 2: activation (no hyphen)

- p. 24, 25: Could you add the information on the vertical resolution of the FTIR measurements to one of these tables?

- p. 39: pane -> panel 


\section{References}

Akiyoshi, H., Nakamura, T., Miyasaka, T., Shiotani, M., and Suzuki, M.: A nudged chemistryclimate model simulation of chemical constituent distribution at northern high-latitude stratosphere observed by SMILES and MLS during the 2009/2010 stratospheric sudden warming, J. Geophys. Res., 121, 1361-1380, https://doi.org/10.1002/2015JD023334, https://agupubs. onlinelibrary.wiley.com/doi/abs/10.1002/2015JD023334, 2016.

Chipperfield, M. P., Bekki, S., Dhomse, S., Harris, N. R. P., Hassler, B., Hossaini, R., Steinbrecht, W., Thieblemont, R., and Weber, M.: Detecting recovery of the stratospheric ozone layer, Nature, 549, 211-218, https://doi.org/\{10.1038/nature23681\}, 2017.

Crutzen, P. J., Müller, R., Brühl, C., and Peter, T.: On the potential importance of the gas phase reaction $\mathrm{CH}_{3} \mathrm{O}_{2}+\mathrm{ClO} \rightarrow \mathrm{ClOO}+\mathrm{CH}_{3} \mathrm{O}$ and the heterogeneous reaction $\mathrm{HOCl}+\mathrm{HCl} \rightarrow$ $\mathrm{H}_{2} \mathrm{O}+\mathrm{Cl}_{2}$ in "ozone hole" chemistry, Geophys. Res. Lett., 19, 1113-1116, https://doi.org/ 10.1029/92GL01172, 1992.

Douglass, A. R., Schoeberl, M. R., Stolarski, R. S., Waters, J. W., Russell III, J. M., Roche, A. E., and Massie, S. T.: Interhemispheric differences in springtime production of $\mathrm{HCl}$ and $\mathrm{ClONO}_{2}$ in the polar vortices, J. Geophys. Res., 100, 13 967-13978, 1995.

Farman, J. C., Gardiner, B. G., and Shanklin, J. D.: Large losses of total ozone in Antarctica reveal seasonal $\mathrm{ClO}_{x} / \mathrm{NO}_{x}$ interaction, Nature, 315, 207-210, 1985.

Froidevaux, L., Kinnison, D. E., Wang, R., Anderson, J., and Fuller, R. A.: Evaluation of CESM1 (WACCM) free-running and specified dynamics atmospheric composition simulations using global multispecies satellite data records, Atmos. Chem. Phys., 19, 47834821, https://doi.org/10.5194/acp-19-4783-2019, https://www.atmos-chem-phys.net/19/4783/ 2019/, 2019.

Gernandt, H.: The vertical ozone distribution above the GDR research base, Antarctica in 1985, Geophys. Res. Lett., 14, 84-86, 1987.

Grooß, J.-U., Brautzsch, K., Pommrich, R., Solomon, S., and Müller, R.: Stratospheric ozone chemistry in the Antarctic: What controls the lowest values that can be reached and their recovery?, Atmos. Chem. Phys., 11, 12217-12226, 2011.

Grooß, J.-U., Müller, R., Spang, R., Tritscher, I., Wegner, T., Chipperfield, M. P., Feng, W., Kinnison, D. E., and Madronich, S.: On the discrepancy of $\mathrm{HCl}$ processing in the core of the wintertime polar vortices, Atmos. Chem. Phys., pp. 8647-8666, https://doi.org/10.5194/ acp-18-8647-2018, 2018.

Interactive

comment
Printer-friendly version

Discussion paper 
Hoppe, C. M., Hoffmann, L., Konopka, P., Grooß, J.-U., Ploeger, F., Günther, G., Jöckel, P., and Müller, R.: The implementation of the CLaMS Lagrangian transport core into the chemistry climate model EMAC 2.40.1: application on age of air and transport of long-lived trace species, Geosci. Model Dev., 7, 2639-2651, https://doi.org/10.5194/gmd-7-2639-2014, http://www.geosci-model-dev.net/7/2639/2014/, 2014.

Khosrawi, F., Müller, R., Proffitt, M. H., Ruhnke, R., Kirner, O., Jöckel, P., Grooß, J.-U., Urban, J., Murtagh, D., and Nakajima, H.: Evaluation of CLaMS, KASIMA and ECHAM5/MESSy1 simulations in the lower stratosphere using observations of Odin/SMR and ILAS/ILAS-II, Atmos. Chem. Phys., 9, 5759-5783, 2009.

Lee, A., Roscoe, H., Jones, A., Haynes, P., Shuckburgh, E., Morrey, M., and Pumphrey, H.: The impact of the mixing properties within the Antarctic stratospheric vortex on ozone loss in spring,, J. Geophys. Res., 106, 3203-3211, https://doi.org/10.1029/2000JD900398, 2001.

Müller, R., Grooß, J.-U., Zafar, A. M., Robrecht, S., and Lehmann, R.: The maintenance of elevated active chlorine levels in the Antarctic lower stratosphere through $\mathrm{HCl}$ null cycles, Atmos. Chem. Phys., 18, 2985-2997, https://doi.org/10.5194/acp-18-2985-2018, https://www. atmos-chem-phys.net/18/2985/2018/, 2018.

Oelhaf, H., v. Clarmann, T., Fischer, H., Friedl-Vallon, F., Fritzsche, C., Linden, A., Piesch, C., Seefeldner, M., and Völker, W.: Stratospheric $\mathrm{ClONO}_{2}$ and $\mathrm{HNO}_{3}$ profiles inside the Arctic vortex from MIPAS-B limb emission spectra obtained during EASOE, Geophys. Res. Lett., 21, 1263-1266, https://doi.org/10.1029/93GL01303, 1994.

Prather, M. J.: More rapid ozone depletion through the reaction of $\mathrm{HOCl}$ with $\mathrm{HCl}$ on polar stratospheric clouds, Nature, 355, 534-537, 1992.

Solomon, S., Portmann, R. W., Sasaki, T., Hofmann, D. J., and Thompson, D. W. J.: Four decades of ozonesonde measurements over Antarctica, J. Geophys. Res., 110, D21311, https://doi.org/10.1029/2005JD005917, 2005.

Solomon, S., Kinnison, D., Bandoro, J., and Garcia, R.: Simulation of polar ozone depletion: An update, J. Geophys. Res., 120, 7958-7974, https://doi.org/10.1002/2015JD023365, 2015.

Strahan, S. E., Douglass, A. R., Newman, P. A., and Steenrod, S. D.: Inorganic chlorine variability in the Antarctic vortex and implications for ozone recovery, J. Geophys. Res., https://doi.org/10.1002/2014JD022295, http://dx.doi.org/10.1002/2014JD022295, 2014.

Tilmes, S., Müller, R., Grooß, J.-U., Nakajima, H., and Sasano, Y.: Development of tracer relations and chemical ozone loss during the setup phase of the polar vortex, J. Geophys. Res., 111, D24S90, https://doi.org/10.1029/2005JD006726, 2006. 
Toon, G. C. and Farmer, C. B.: Detection of $\mathrm{HOCl}$ in the Antarctic stratosphere, Geophys. Res. Lett., 16, 1375-1377, https://doi.org/10.1029/GL016i012p01375, https://agupubs.onlinelibrary. wiley.com/doi/abs/10.1029/GL016i012p01375, 1989.

von Clarmann, T., Fischer, H., Friedl-Vallon, F., Linden, A., Oelhaf, H., Piesch, C., Seefeldner, M., and Völker, W.: Retrieval of Stratospheric $\mathrm{O}_{3}, \mathrm{HNO}_{3}$ and $\mathrm{CIONO}_{2}$ profiles from 1992 MIPAS-B limb emission spectra: method, results and error analysis, J. Geophys. Res., 98, 20 495-20 506, 1993.

WMO: Scientific assessment of ozone depletion: 2018, Global Ozone Research and Monitoring Project-Report No. 58, Geneva, Switzerland, 2019.

Zafar, A. M., Müller, R., Grooß, J.-U., Robrecht, S., Vogel, B., and Lehmann, R.: The relevance of reactions of the methyl peroxy radical $\left(\mathrm{CH}_{3} \mathrm{O}_{2}\right)$ and methylhypochlorite $\left(\mathrm{CH}_{3} \mathrm{OCl}\right)$ for Antarctic chlorine activation and ozone loss, Tellus B: Chemical and Physical Meteorology, 70, 1-18, https://doi.org/10.1080/16000889.2018.1507391, https://doi.org/10.1080/16000889. 2018.1507391, 2018.

Interactive comment on Atmos. Chem. Phys. Discuss., https://doi.org/10.5194/acp-2019-443, 2019. 